Article

\title{
Intra- and Inter-Specific Crosses among Centaurea aspera L. (Asteraceae) Polyploid Relatives-Influences on Distribution and Polyploid Establishment
}

\author{
Alfonso Garmendia ${ }^{1,+}+{ }^{+}$, María Ferriol ${ }^{1,+}{ }^{+}$, David Benavent ${ }^{2}$, P. Pablo Ferrer-Gallego ${ }^{3}(\mathbb{C}$ and \\ Hugo Merle 2,*(D) \\ 1 Instituto Agroforestal Mediterráneo, Universitat Politècnica de València, ES-46022 Valencia, Spain; \\ algarsal@upvnet.upv.es (A.G.); mafermo@upvnet.upv.es (M.F.) \\ 2 Departamento de Ecosistemas Agroforestales, Universitat Politècnica de València, ES-46022 Valencia, Spain; \\ dabema@etsiamn.upv.es \\ 3 Servicio de Vida Silvestre, Centro para la Investigación y la Experimentación Forestal - VAERSA, \\ Generalitat Valenciana, Avda. Comarques del País Valencià 114, Quart de Poblet, ES-46930 Valencia, Spain; \\ flora.cief@gva.es \\ * Correspondence: humerfa@upvnet.upv.es; Tel.: +34-962849421 \\ + Equal contributors.
}

Received: 18 July 2020; Accepted: 2 September 2020; Published: 3 September 2020

\begin{abstract}
How polyploids become established is a long-debated question, especially for autopolyploids that seem to have no evolutionary advantage over their progenitors. The Centaurea aspera polyploid complex includes diploid C. aspera and two related tetraploids $C$. seridis and C. gentilii. Our purpose was to study the mating system among these three taxa and to analyze its influence on polyploid establishment. The distribution and ploidy level of the Moroccan populations, and forced intra- and inter-specific crosses were assessed. Allotetraploid C. seridis produced more cypselae per capitulum in the intra-specific crosses. It is a bigger plant and autogamous, and previous studies indicated that selfing forces the asymmetric formation of sterile hybrids. All these characteristics help C. seridis to avoid the minority-cytotype-exclusion effect and become established. Inter-specific hybridization was possible between C. aspera and C. gentilii, and with the symmetric formation of hybrids. However, $49 \%$ of the hybrid cypselae were empty, which probably reveals postzygotic barriers. Autotetraploid C. gentilii produced the same number of cypselae per capitulum as those of the diploid parental, has an indistinguishable field phenotype, is allogamous, and symmetrically produces hybrids. Therefore, $C$. gentilii does not seem to have the same competitive advantages as those of $C$. seridis.
\end{abstract}

Keywords: allopolyploid; autopolyploid; cytotype; tetraploid; triploid; polyploidy; minority-cytotype exclusion; postzygotic barriers; Centaurea; Asteraceae

\section{Introduction}

Polyploidy is one of the most important and ubiquitous driving forces in plant evolution [1-3]. In a climate-change context, Levin (2019) proposed that polyploidization will be one of the most frequent speciation modes in the next 500 years, with an increase in the percentage of polyploid plants from $35 \%$ today to more than $50 \%$. This hypothesis is related to the fact that polyploidy can occur in sympatry, and neopolyploids can be established in only a few generations; therefore, they might be reinforced in rapidly changing scenarios [4].

Autopolyploids are considered to form by genome multiplication, while allopolyploids derive from hybridization between species with differentiated genomes, either by chromosome doubling 
after the fusion of reduced or unreduced gametes. However, this classification has long since been discussed. The term "segmental allopolyploid" is used to describe polyploids that do not exhibit strict bivalent formation across all chromosomes or disomic inheritance at all loci [5]. While autopolyploids and allopolyploids are identified according to chromosome pairing behavior (formation of multivalents and bivalents in meiosis, respectively), Stebbins (1947) considered that the parents of segmental allopolyploids occupied an intermediate level of chromosomal divergence between those of autopolyploids and allopolyploids [6].

How polyploids establish remains a debated question in evolutionary biology [7], especially autopolyploids that seem to have no clear evolutionary advantage over their diploid progenitors $[8,9]$. As a result, for years, autopolyploids were considered rare in nature, representing evolutionary dead ends $[10,11]$. However, recent studies showed that autopolyploids are more abundant than expected [12,13], and their abundance could have been underestimated due to recognition difficulties, as their phenotypes are similar or identical to their diploid progenitors [14].

To analyze the evolutionary significance of polyploidy, Levy and Feldman (2004) differentiated short-term "revolutionary changes", related mainly to the establishment of polyploids, and long-term "evolutionary changes", related more to their expansion and persistence. In this sense, allopolyploids undergo extensive genomic changes in first generations [15-17], while autopolyploids may experience fewer structural changes [13,18]. Unlike nascent autopolyploids, well-established autopolyploids can also show substantial genome reorganization compared to their diploid relatives $[8,13,19]$. Along with these genomic changes, functional reorganization of the gene-expression network may also occur, which is much more evident in allopolyploids than in autopolyploids [20-22]. Recent studies considered autopolyploidy as a macromutation with epigenetic consequences [23]. In general, hybridization (included in allopolyploid formation) seems to trigger significant changes, while only genome doubling maintains a similar state to that of its diploid progenitor $[6,8,24]$. In addition, autopolyploids have always been expected to be less fertile than allopolyploids are given the meiotic irregularities caused by multivalent chromosome pairing [25]. However, more recent studies revealed that aberrant meiosis affects both auto- and allopolyploids $[17,26]$. Such irregularities may be overcome through the frequent turnover of reproduction modes (from sexual to apomictic reproduction) $[27,28]$ or the evolution of a stabilized form of meiotic asymmetry in chromosome inheritance [29].

The union of unreduced (2n) gametes is thought to be the commonest pathway for natural polyploid formation [30] through either the fusion of two unreduced gametes or a "triploid bridge" that can generate tetraploid progeny through selfing or backcrossing [31]. Triploids are often sterile [32,33], but they can sometimes produce a large proportion of fertile unreduced gametes that increases the possibility of tetraploid formation [31,34]. The production of unreduced gametes has been proven heritable, governed by a few genes, and increasing with environmental stress, such as heat, frost, water deficit, and herbivory $[8,35,36]$. This is in accordance with the higher frequency of polyploids found in habitats affected by climate fluctuations and disruptions [37-39]. Some studies pointed out that polyploid species are over-represented in previously glaciated regions, while diploids are more frequent in disjunct refugial areas [40,41]. Under these abiotic conditions, polyploid formation can be recurrent and with multiple origins. Despite all this knowledge, the establishment of neopolyploids and especially neo-auto-polyploids remains unclear.

Centaurea (Asteraceae) is a taxonomically intricate genus due to the existence of polyploidy, descending dysploidy cycles, and hybridization events, with a large number of polyploid complexes [42,43]. The Centaurea aspera L. polyploid complex has long since been studied, and it is mainly distributed in coastal habitats of Spain and Morocco. [32,38,44-51]. What makes the C. aspera polyploid complex so interesting is that it is made up of natural populations of the parental diploid (C. aspera L. $2 x=22$ ), an allotetraploid (C. seridis L. $4 x=44)$ and an autotetraploid (C. gentilii Braun-Blanq. and Maire $4 x=44)$. Chromosome counts were previously performed by cytological techniques in the three studied species [49]. Centaurea seridis and C. aspera can coexist in Spanish natural-contact zones to produce triploid hybrids $(C . \times$ subdecurrens Pau $3 x=33)$ [32]. Similarly, 
C. gentilii and C. seridis can coexist in Morocco to produce tetraploid hybrids (C. $\times$ paucispina (Ferriol, Merle and Garmendia) P.P. Ferrer $4 x=44$ ) $[46,49]$. The existence of these taxa with different ploidy levels, geographical distributions, fertility, and mating systems allows for direct comparison to analyze their competitive advantages or disadvantages.

In this context, we aimed to study the mating system and reproductive barriers among Centaurea aspera and its polyploid relatives, allotetraploid C. seridis $(4 \mathrm{x}=44)$, and autotetraploid C. gentilii $(4 x=44)$, and to analyze their geographical distribution. We specifically addressed the following questions: (i) what are the geographical distribution and ploidy level of the Moroccan populations? (ii) Do the seed sets that derive from the intra-specific crosses within each taxon differ? (iii) Is hybridization between C. aspera and C. gentilii possible? (iv) Are the seed sets per capitulum that derive from intraand inter-specific crosses different? We combined previously published information with the new data to offer an overview of the geographical distribution and reproductive behavior of the three species and their hybrids.

\section{Results}

\subsection{Centaurea gentilii and C. seridis Geographical Distribution and Ploidy Level in Morocco}

The northernmost observed locality of Centaurea gentilii was Zaouiat el Kourati (52 km north of Essaouira). No new populations of $C$. gentilii were found on the Atlantic northern coast (from Casablanca to Tangier) and the Mediterranean coast (from Tangier to Nador). Instead, populations of C. seridis were frequently found in these coastal habitats, with Essaouira being the southernmost population.

As all the Moroccan sampled individuals were tetraploid (4×), and in accordance with the collected data, C. gentilii is represented by tetraploid populations on the southern Atlantic coast of Morocco, while $C$. seridis is represented by tetraploid populations on the northern Atlantic and Mediterranean Moroccan coasts. There is a small contact zone where both species coexist north of Essaouira (Zaouiat el Kourati; Figure 1).

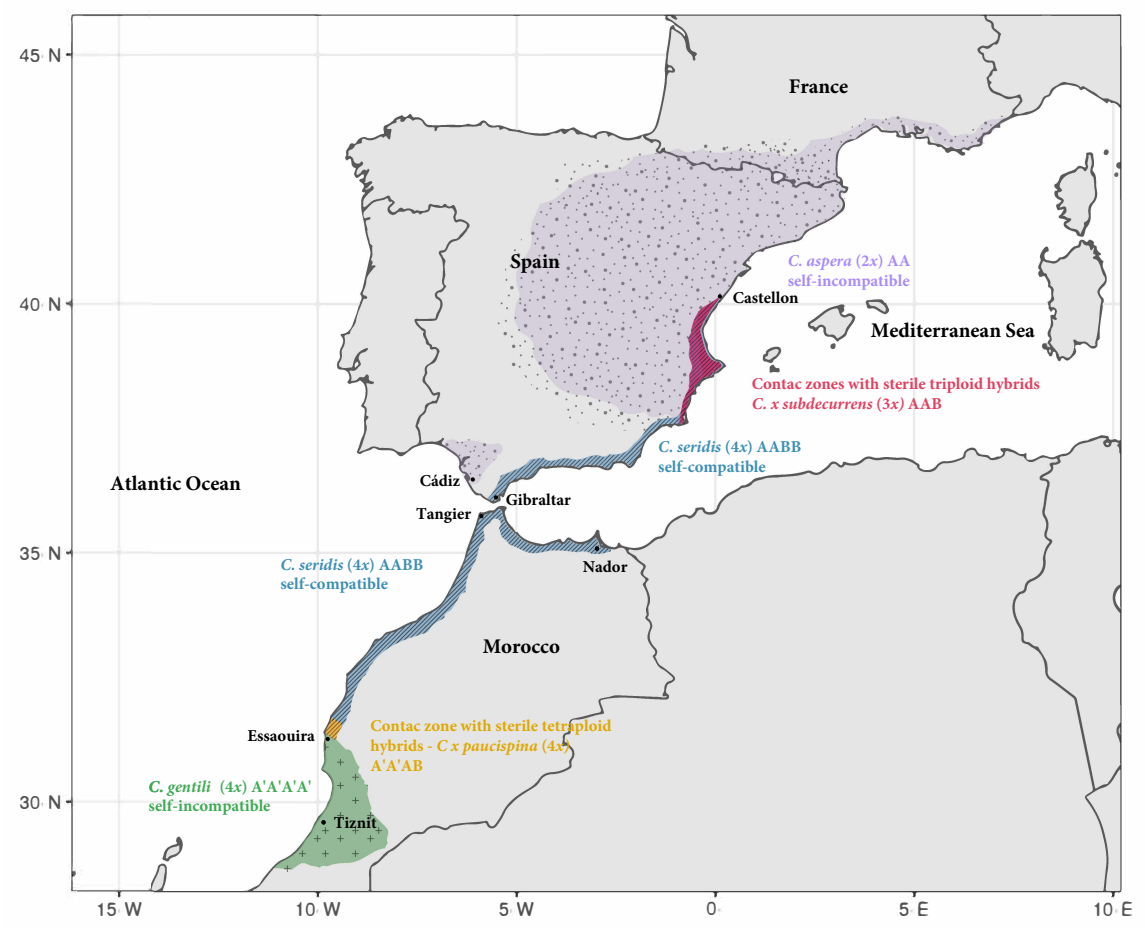

Figure 1. Schematic geographical distribution of Centaurea gentilii, C. seridis, and C. aspera with natural-contact zones with hybrids (Spain and Morocco). Spanish distribution of C. aspera, C. seridis, and triploid hybrids (C. $\times$ subdecurrens) was taken from previous works $[32,38,49]$. 


\subsection{Cypselae Production in Intra-Specific Crosses}

In all, 228 intra-specific crosses were performed: 48 for C. seridis, 98 for C. aspera, and 82 for C. gentilii. Within C. seridis and C. aspera, intra-specific crosses did not show any significant differences among populations (Figures S1 and S2, respectively). Intra-specific crosses between Centaurea gentilii individuals from Zaouiat performed in 2018 (zz18) resulted in an unexpected small number of cypselae, with significant differences to Zaouiat intra-specific crosses performed in 2019 (zz19) (Figure S3). All plants were sown in the greenhouse in 2018, but the Zaouiat plants grew later, and bloomed after spring in July and August when very high temperatures were recorded. This circumstance was probably the cause of the unusual infertility of this treatment in this year. Therefore, this dataset was removed from analysis, although results with or without the zz18 data did not significantly differ (Figure S4). Centaurea seridis produced significantly more cypselae per capitulum $(4.88 \pm 0.64$; mean $\pm \mathrm{SE}$ ) than $C$. aspera $(2.62 \pm 0.35)$ and C. gentilii $(3.09 \pm 0.51)$ did $(p$-value $=0.002$; Figure 2 and Table 1). Twenty-five intra-specific cypselae per species were analyzed to confirm the ploidy level and percentage of empty cypselae. All analyzed intra-specific cypselae had the same ploidy level as the progenitors did, and less than $5 \%$ empty cypselae.

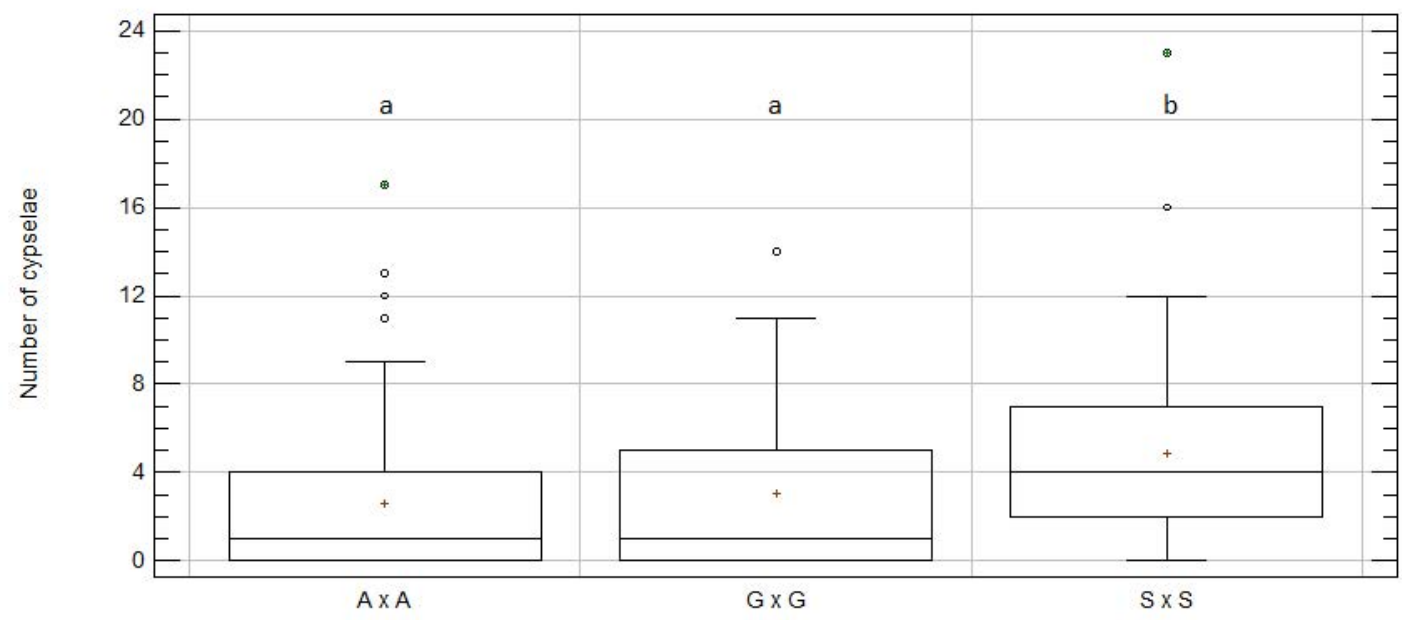

Figure 2. Box and whisker plot for "taxon" effect on number of cypselae per capitulum for intra-specific treatment. A $\times$ A, C. aspera intra-specific crosses; $\mathrm{G} \times \mathrm{G}, \mathrm{C}$. gentilii intra-specific crosses; $\mathrm{S} \times \mathrm{S}, \mathrm{C}$. seridis intra-specific crosses. Boxes show 25 th and 75 th percentiles. Lines in boxes denote median values. Columns with distinct letters significantly differ from one another at $p \leq 0.05$, Degrees of freedom (Df) = 203; Kruskal-Wallis $(\mathrm{KW})$ value $=12.6 ; p$-value $=0.002$. Zaouiat data from 2018 were excluded.

Table 1. Number of cypselae obtained per capitulum in intra-specific treatment per taxon.

\begin{tabular}{cccccccc}
\hline Taxon & N & Mean & SE & KW & Skew & Kurtosis & Cypselae_sum \\
\hline $\mathrm{A} \times \mathrm{A}$ & 98 & 2.62 & 0.35 & $\mathrm{a}$ & 6.59 & 5.50 & 257 \\
\hline $\mathrm{G} \times \mathrm{G}$ & 58 & 3.09 & 0.51 & $\mathrm{a}$ & 3.59 & 0.33 & 179 \\
\hline $\mathrm{S} \times \mathrm{S}$ & 48 & 4.88 & 0.64 & $\mathrm{~b}$ & 4.94 & 7.01 & 234 \\
\hline Total & 204 & 3.28 & 0.28 & - & 9.10 & 9.31 & 670
\end{tabular}

A $\times$ A, C. aspera intra-specific crosses; $G \times G, C$. gentilii intra-specific crosses; $\mathrm{S} \times \mathrm{S}$, C. seridis intra-specific crosses; $\mathrm{N}$, number of treated capitula; SE, standard error; KW, Kruskal-Wallis test for effect of groups on mean number of cypselae $p$-value $=0.00183931(\mathrm{Df}=203 ; \mathrm{KW}$-value $=12.5967)$. Treatments with distinct letters significantly differed from one another at $p \leq 0.05$; Cypselae_sum, total number of cypselae obtained per treatment. Zaouiat data from 2018 were excluded. 


\subsection{Intra-Specific Cypselae Production between and within Populations in C. aspera and C. gentilii}

In 2019, intra-specific crosses in C. aspera and C. gentilii were specifically repeated to compare within and between populations' seed sets. Nonsignificant differences in the number of cypselae per capitulum were found among treatments (Figure 3 and Table 2).

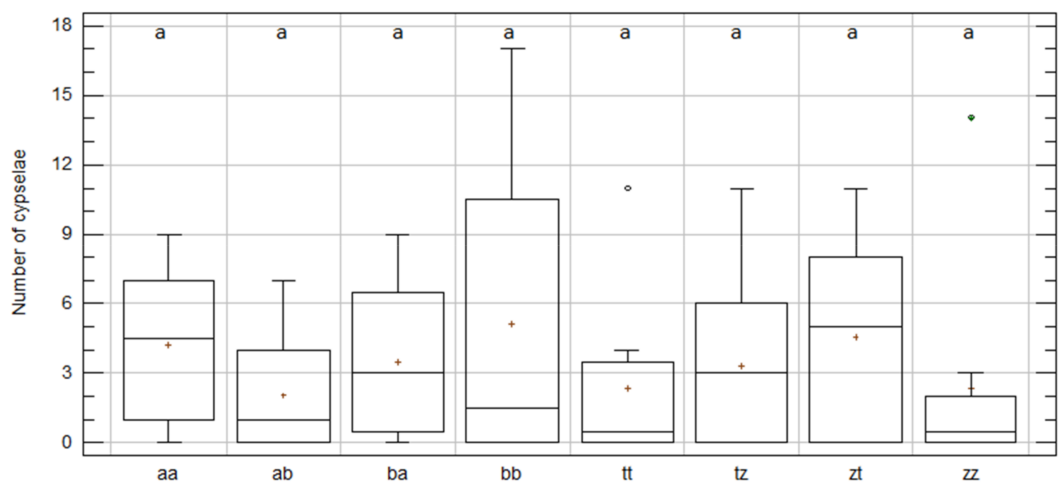

Figure 3. Box and whisker plots for "gamete-origin" effect on number of cypselae per capitulum for intra-specific 2019 treatment. C. aspera populations: aa, ovules and pollen from El Saler; ab, ovules from El Saler and pollen from Chulilla; ba, ovules from Chulilla and pollen from El Saler; bb, ovules and pollen from Chulilla; C. gentilii populations: $t \mathrm{t}$, ovules and pollen from Tamri; $\mathrm{tz}$, ovules from Tamri and pollen from Zaouiat; zt, ovules from Zaouiat and pollen from Tamri; zz, ovules and pollen from Zaouiat. Boxes show 25th and 75th percentiles. Lines in boxes show median values. Columns with same letter did not significantly differ from one another at $p \leq 0.05$, Df $=97$; KW value $=5.54$; $p$-value $=0.59$.

Table 2. Number of cypselae obtained per capitulum in C. aspera and C. gentilii for intra-specific 2019 treatment per gamete origin.

\begin{tabular}{ccccccccc}
\hline Location & Sp. & N & Mean & SE & KW & Skew & Kurtosis & Cypselae_sum \\
\hline aa & C. aspera & 8 & 4.25 & 1.28 & a & -0.03 & -1.23 & 34 \\
\hline ab & C. aspera & 16 & 2.06 & 0.59 & a & 1.52 & -0.36 & 41 \\
\hline ba & C. aspera & 16 & 3.50 & 0.79 & a & 0.60 & -1.11 & 33 \\
\hline bb & C. aspera & 8 & 5.13 & 2.39 & a & 1.16 & -0.33 & 56 \\
\hline tt & C. gentilii & 8 & 2.38 & 1.35 & a & 2.34 & 2.47 & 19 \\
\hline tz & C. gentilii & 17 & 3.35 & 0.84 & a & 1.49 & -0.19 & 19 \\
\hline zt & C. gentilii & 17 & 4.59 & 1.03 & a & 0.42 & -1.34 & 57 \\
\hline zz & C. gentilii & 8 & 2.38 & 1.70 & a & 2.99 & 3.98 & 78 \\
\hline Total & & 98 & 3.44 & 0.40 & - & 4.57 & 1.39 & 337 \\
\hline
\end{tabular}

C. aspera populations: aa, ovules and pollen from El Saler; ab, ovules from El Saler and pollen from Chulilla; ba, ovules from Chulilla and pollen from El Saler; bb, ovules and pollen from Chulilla; C. gentilii populations: $\mathrm{tt}$, ovules and pollen from Tamri; tz, ovules from Tamri and pollen from Zaouiat; zt, ovules from Zaouiat and pollen from Tamri; zz, ovules and pollen from Zaouiat. N, number of treated capitula; SE, standard error; KW, Kruskal-Wallis test for the effect of groups on the mean number of cypselae $p$-value $=0.593788(\mathrm{Df}=97 ; \mathrm{KW}$ value $=5.54478)$. The treatments with the same letter do not significantly differ from one another at $p \leq 0.05$; Cypselae_sum, total number of cypselae obtained per treatment.

The crosses within the populations in C. gentilii (tt and $\mathrm{zz}$ ) gave fewer cypselae per capitulum $(2.38 \pm 1.05)$ than between populations $(3.97 \pm 0.64)$, but with no statistical significance (Figure S5). The opposite happened for $C$. aspera, with more cypselae within $(4.69 \pm 1.32)$ than between populations (2.78 \pm 0.5$)$ and, once again, with no significant differences (Figure S5). Regardless of gamete origin, the C. aspera and C. gentilii intra-specific crosses performed in 2019 gave a similar number of cypselae 
per capitulum with no significant differences $(3.42 \pm 0.56 \mathrm{~A} \times \mathrm{A}$ vs. $3.46 \pm 0.57 \mathrm{G} \times \mathrm{G}$; $p$-value $=0.94$; Figure S5).

\subsection{Inter-Specific Crosses between C. aspera and C. gentilii}

Hybrid cypselae were obtained from the inter-specific treatment between $C$. aspera and $C$ gentilii. Cypselae were obtained on both: C. aspera capitula (ovules from C. aspera and pollen form C. gentilii; $\mathrm{A} \times \mathrm{G}$ ) and $C$. gentilii capitula (ovules from $C$. gentilii and pollen from C. aspera; $\mathrm{G} \times \mathrm{A}$ ). Both species acted as 'mothers'.

Like intra-specific treatments, the inter-specific treatments involving the $C$. gentilii population of Zaouiat, performed in 2018 (zx18), produced an extremely small number of cypselae. This denotes significant differences with the same treatment performed in 2019 (zx19) and with that performed in 2018 using the C. gentilii individuals from the Tamri population (tx18) (Figure S6). For this reason, the zx18 dataset was removed before running the analysis.

Centaurea aspera and C. gentilii produced a similar mean number of hybrid cypselae per capitulum when the inter-specific crosses were forced, and no significant differences appeared $(1.91 \mathrm{~A} \times \mathrm{G}$ vs. $1.93 \mathrm{G} \times \mathrm{A} ; p$-value $=0.28$; Figure 4 and Table 3 ), that is, hybrids were symmetrically produced. When data were separately analyzed for each year, similar results were obtained for 2018 and 2019, with no significant differences between $\mathrm{A} \times \mathrm{G}$ and $\mathrm{G} \times \mathrm{A}$ (Figure $\mathrm{S7}$ ).

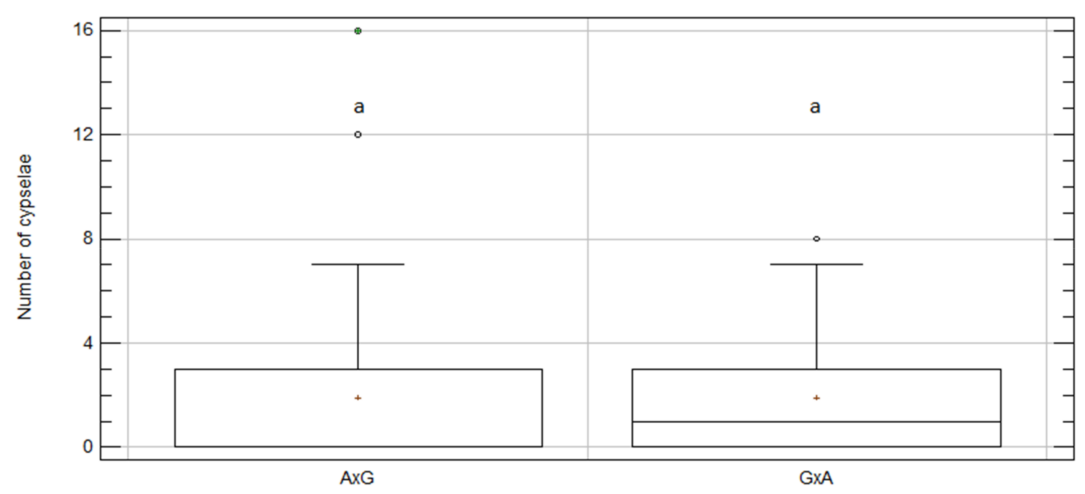

Figure 4. Box and whisker plot for "mother-taxon" effect on number of cypselae per capitulum for inter-specific treatment between C. aspera and C. gentilii. A $\times$ G, ovules from C. aspera and pollen from C. gentilii; $\mathrm{G} \times \mathrm{A}$, ovules from C. gentilii and pollen from C. aspera. Boxes show 25th and 75th percentiles. Lines in boxes show median values. Columns with same letter did not significantly differ from one another at $p \leq 0.05, \mathrm{Df}=87 ; \mathrm{KW}$ value $=1.18 ; p$-value $=0.28$.

Table 3. Number of hybrid cypselae per capitulum for inter-specific treatment between C. aspera and C. gentilii for mother taxa.

\begin{tabular}{cccccccc}
\hline Mother Taxa & N & Mean & SE & KW & Skew & Kurtosis & Cypselae_sum \\
\hline $\mathrm{A} \times \mathrm{G}$ & 44 & 1.91 & 0.51 & a & 6.67 & 9.41 & 84 \\
\hline $\mathrm{G} \times \mathrm{A}$ & 44 & 1.93 & 0.36 & a & 2.89 & 0.10 & 85 \\
\hline Total & 88 & 1.92 & 0.31 & - & 8.31 & 12.01 & 169
\end{tabular}

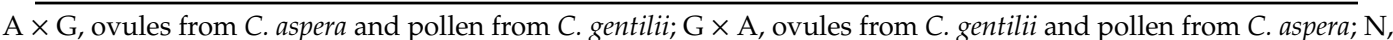
number of treated capitula; SE, standard error; KW, Kruskal-Wallis test for the effect of groups on the mean number of cypselae $p$-value $=0.2781$ (Df $=87 ; \mathrm{KW}$ value $=1.17634)$. Treatments with same letter did not significantly differ from one another at $p \leq 0.05$; Cypselae_sum, total number of cypselae obtained per treatment.

\subsection{Offspring Analysis}

We obtained 181 cypselae from inter-specific crosses, 84 in 2018 ( $38 \mathrm{~A} \times \mathrm{G}$ and $46 \mathrm{G} \times \mathrm{A}$ ) and 97 in $2019(58 \mathrm{~A} \times \mathrm{G}$ and $39 \mathrm{G} \times \mathrm{A}$ ). Of these, a large number of empty (E) cypselae (48.6\%) were found. The inter-specific offspring ploidy level was analyzed, and all individuals that derived from intact-full 
cypselae were triploid (3x) except for a single $G \times$ A tetraploid cypsela obtained in 2018. In 2018, there were fewer full $A \times G$ cypselae than expected, while there were fewer $G \times A$ empty cypselae than expected in 2019 (Figure 5).

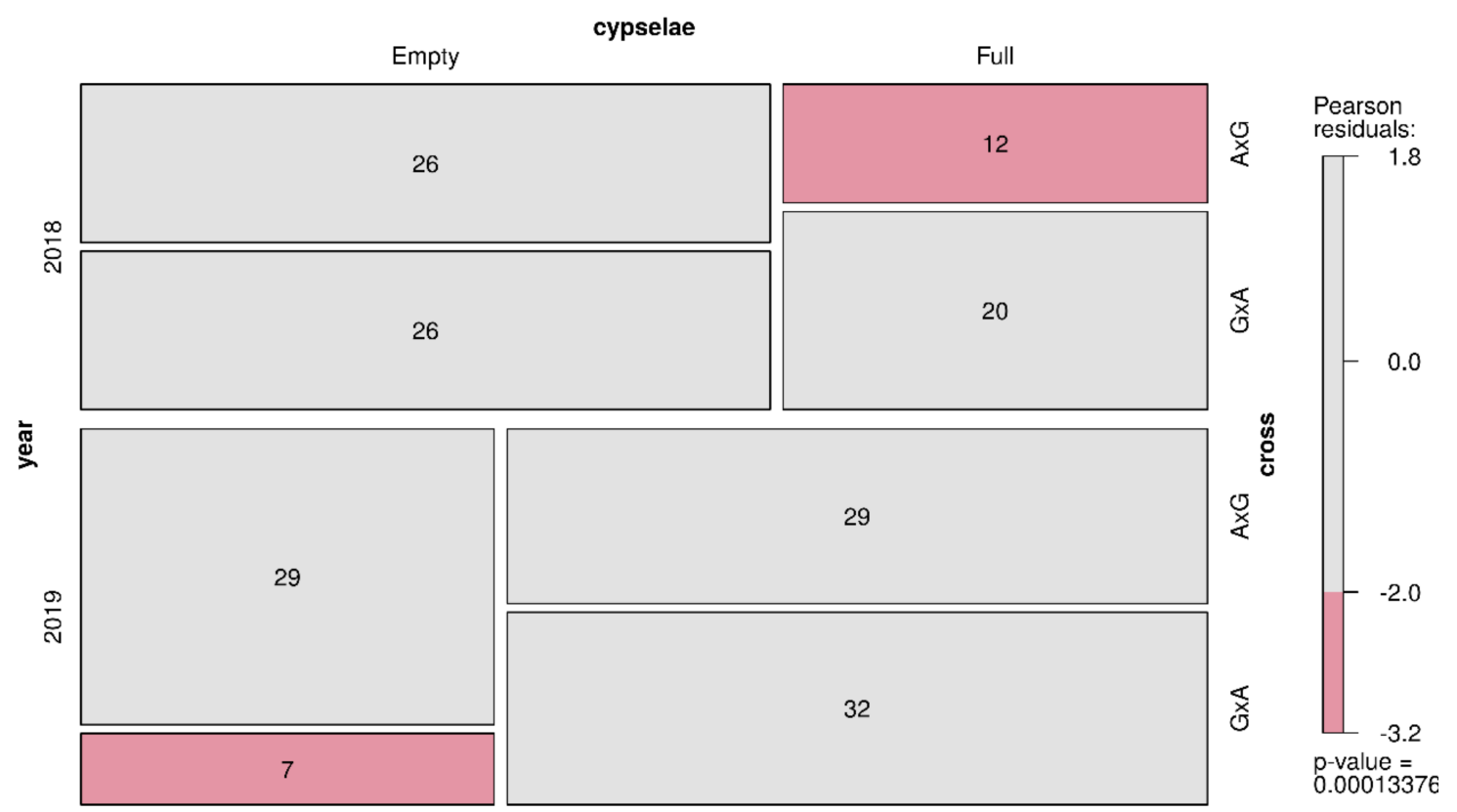

Figure 5. Mosaic plot of number of empty/full cypselae in each year for each crossing type. Red depicts significantly lower frequencies than expected. Numbers represent cypselae number.

\subsection{Intra- vs. Inter-Specific Treatments}

Intra- and inter-specific treatments were compared within species to analyze if hybrid cypselae production was similar or not to intra-specific cypselae production. In C. aspera, no significant difference was found in the average number of cypselae per capitulum between intra- and inter-specific crosses (Figure 6 and Table 4). The inter-specific cross $(A \times G)$ produced fewer cypselae per capitulum (1.91 \pm 0.51$)$ than the intra-specific cross did $(2.62 \pm 0.35)$, with no significant differences $(\mathrm{KW} p$ value $=0.07)$. This tendency was consistent in both years (Figure S8).

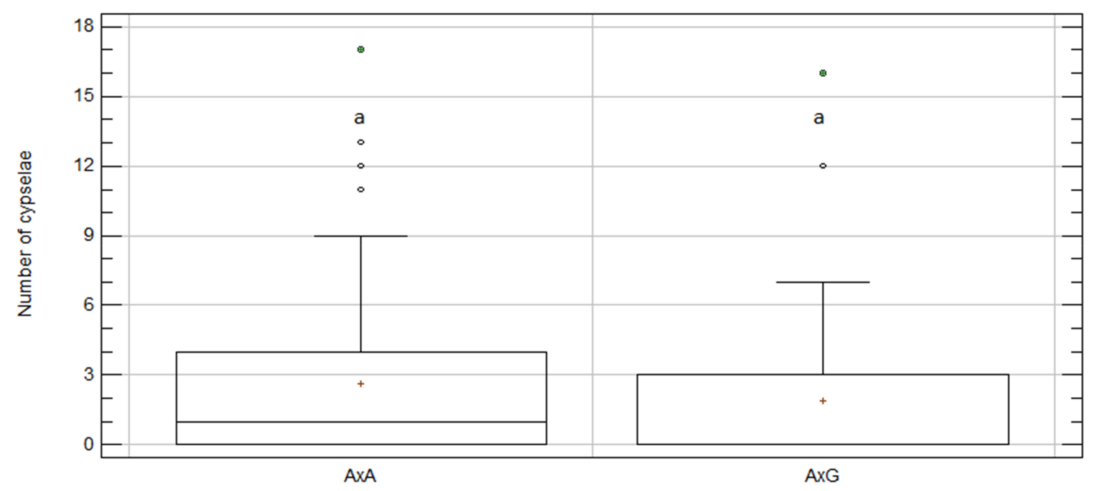

Figure 6. Box and whisker plot for "intra-/inter-specific-treatment" effect on number of cypselae per capitulum for C. aspera regardless of year. $A \times A, C$. aspera intra-specific treatment; $A \times G$, inter-specific treatment with ovules from C. aspera and pollen from C. gentilii. Boxes show 25th and 75th percentiles. Lines in boxes show median values. Columns with same letter did not significantly differ from one another at $p \leq 0.05 ; \mathrm{Df}=141 ; \mathrm{KW}$ value $=3.28 ; p$-value $=0.07$. 
Table 4. Average number of cypselae per capitulum for intra- and inter-specific C. aspera crosses per treatment.

\begin{tabular}{cccccccc}
\hline Treatment & N & Mean & SE & KW & Skew & Kurtosis & Cypselae_sum \\
\hline $\mathrm{A} \times \mathrm{A}$ & 98 & 2.62 & 0.35 & $\mathrm{a}$ & 6.59 & 5.50 & 257 \\
\hline $\mathrm{A} \times \mathrm{G}$ & 44 & 1.91 & 0.51 & $\mathrm{a}$ & 6.67 & 9.41 & 84 \\
\hline Total & 142 & 2.40 & 0.29 & - & 8.92 & 8.60 & 341
\end{tabular}

$\mathrm{A} \times \mathrm{A}, \mathrm{C}$. aspera intra-specific treatment; $\mathrm{A} \times \mathrm{G}$, inter-specific treatment with ovules from C. aspera and pollen from C. gentilii; N, number of treated capitula; SE, standard error; KW, Kruskal-Wallis test for effect of groups on mean number of cypselae $p$-value $=0.0699471(\mathrm{Df}=141 ; \mathrm{KW}$ value $=3.28417)$. Treatments with same letter did not significantly differ from one another at $p \leq 0.05$; Cypselae_sum, total number of cypselae obtained per treatment.

Similarly, in C. gentilii, no significant difference was found in the mean number of cypselae per capitulum between the intra- and inter-specific crosses (Figure 7, Table 5). The inter-specific cross $(\mathrm{G} \times \mathrm{A})$ produced fewer cypselae per capitulum $(1.93 \pm 0.36)$ than the intra-specific cross did $(3.09 \pm 0.51)$, but with no significant difference $(\mathrm{KW} p$-value $=0.3)$. The same tendency was observed for both years (Figure S8).

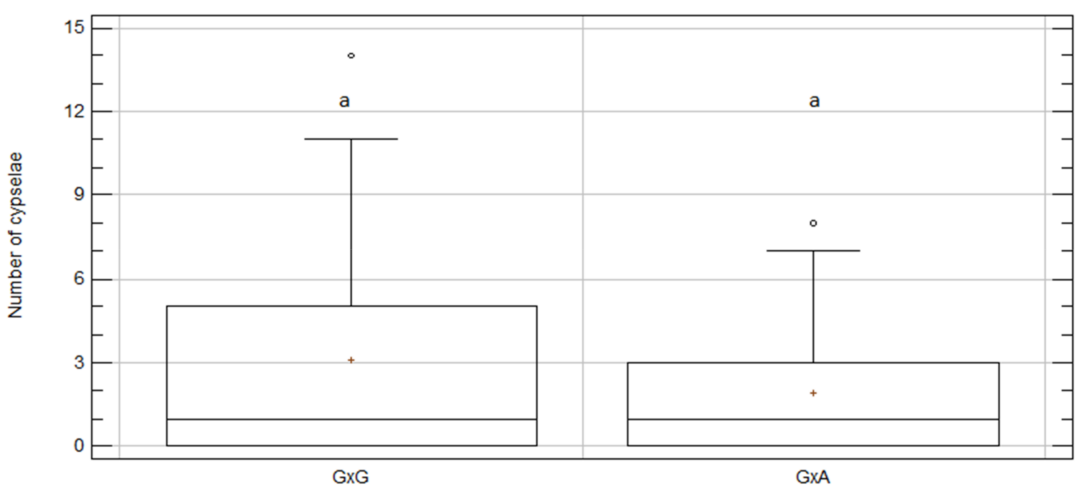

Figure 7. Box and whisker plot for "intra-/inter-specific-treatment" effect on number of cypselae per capitulum for $C$. gentilii regardless of year. $G \times G, C$. gentilii intra-specific treatment; $G \times A$, inter-specific treatment with ovules from $C$. gentilii and pollen from C. aspera. Boxes show 25th and 75th percentiles. Lines in boxes show median values. Columns with same letter did not significantly differ from one another at $p \leq 0.05, \mathrm{Df}=101 ; \mathrm{KW}$ value $=1.06 ; p$-value $=0.3$.

Table 5. Average number of cypselae per capitulum for intra- and inter-specific C. gentilii crosses by treatment.

\begin{tabular}{cccccccc}
\hline Treatment & N & Mean & SE & KW & Skew & Kurtosis & Cypselae_sum \\
\hline $\mathrm{G} \times \mathrm{G}$ & 58 & 3.09 & 0.51 & a & 3.59 & 0.33 & 179 \\
\hline $\mathrm{G} \times \mathrm{A}$ & 44 & 1.93 & 0.36 & a & 2.89 & 0.10 & 85 \\
\hline Total & 102 & 2.59 & 0.33 & - & 5.65 & 2.38 & 264
\end{tabular}

$\mathrm{G} \times \mathrm{G}, \mathrm{C}$. gentilii intra-specific treatment; $\mathrm{G} \times \mathrm{A}$, inter-specific treatment with ovules from C. gentilii and pollen from C. aspera; N, number of treated capitula; SE, standard error; KW, Kruskal-Wallis test for effect of groups on mean number of cypselae, $p$-value $=0.302426(\mathrm{Df}=101 ; \mathrm{KW}$ value $=1.06346)$. Treatments with the same letter do not significantly differ from one another at $p \leq 0.05$; Cypselae_sum, total number of cypselae obtained per treatment.

\section{Discussion}

\subsection{Biogeography of Centaurea aspera, C. gentilii, and C. seridis}

Centaurea gentilii and C. aspera displayed clear allopatric distribution (Figure 1). Diploid C. aspera develops northwardly from Andalusia (S Spain), and tetraploid C. gentilii southwardly from Zaouiat (Essaouira, Morocco). This allopatric distribution of C. aspera and C. gentilii could have been influenced 
by the occurrence of the physical barrier of the Strait of Gibraltar. C. gentilii distribution may represent the southernmost limit of the ancestor species' distribution.

Allotetraploid C. seridis, a coastal specialist that occasionally extends inland [49], occupies the intermediate area between $C$. aspera and C. gentilii. As a result, contact zones with both species arise: to the north of its distribution range, it forms several contact zones with $C$. aspera, in which sterile triploid hybrids (C. $\times$ subdecurrens) are produced [32]. In southern Morocco, a contact zone with $C$. gentilii was found with sterile tetraploid hybrids (C. $\times$ paucispina) [49] (Figure 1 ).

We did not find C. aspera on the SE Mediterranean Spanish coast (form Gibraltar to Almería), but it reappeared on the SW Atlantic Spanish coast (Cádiz), where C. seridis was not present. This could hypothetically indicate that $C$. seridis was able to displace $C$. aspera from the southeastern Spanish coast. Both species still coexist in northern Mediterranean areas from Cartagena to Castellon. Perhaps this coexistence in the north is because $C$. aspera flows from inland populations to the coast. Something similar could have happened on the coast of Morocco between C. seridis and C. gentilii.

\subsection{Mating System of Centaurea aspera Polyploid Complex}

Diploid C. aspera and tetraploid C. gentilii are self-incompatible, while tetraploid C. seridis is self-compatible [32,52]. Inter-specific crosses among the three taxa are possible, but not all of them occur in both directions (Figure 8).

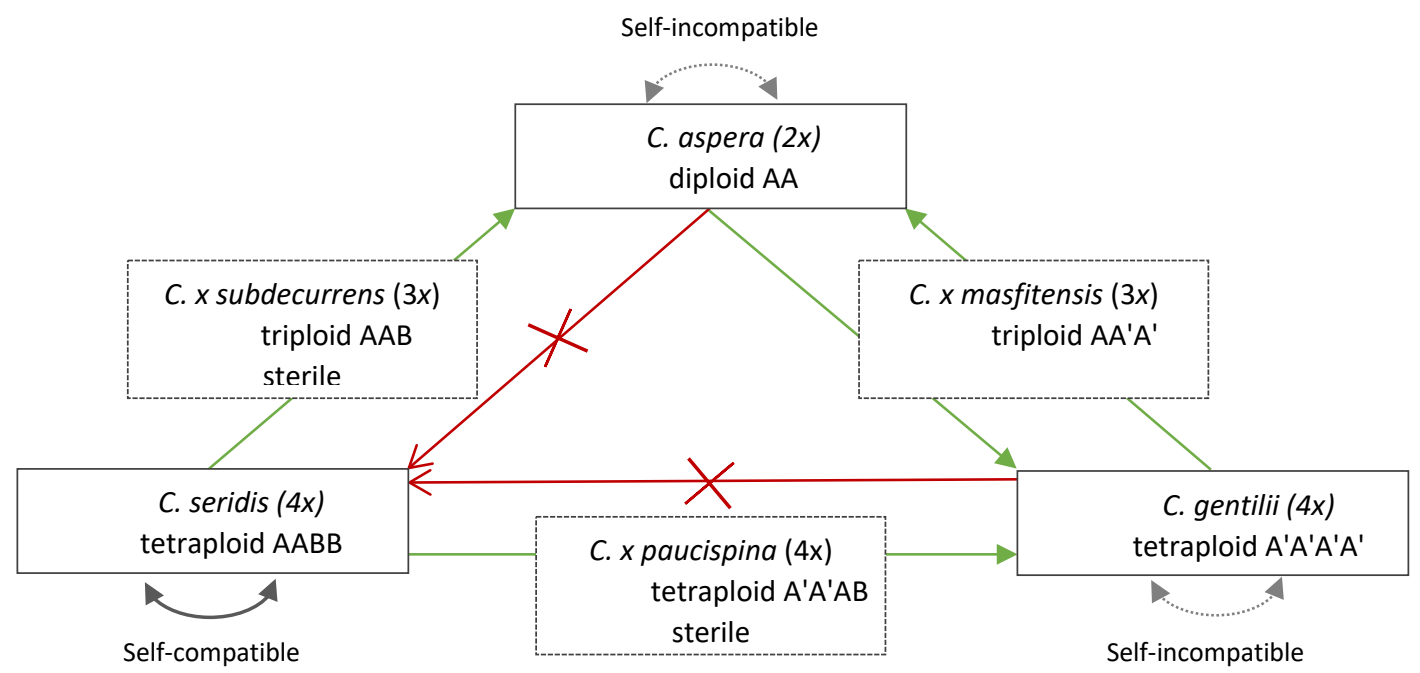

Figure 8. Mating-system scheme within and between three studied species (C. aspera, C. seridis, C. gentilii). Arrows indicate direction of cross father $>$ mother. Green arrows denote crosses with hybrid formation. Red arrows depict blocked crosses due to pollen competition.

Centaurea seridis self-compatibility forces the asymmetric formation of hybrids due to pollen competition on the stigma [32]. Therefore, $C$. seridis $(4 \times)$ and C. aspera $(2 \times)$ cross in natural contact zones with an asymmetric formation of sterile triploid hybrids (C. $\times$ subdecurrens), in which only C. aspera acts as a mother [32]. Similarly, C. seridis $(4 \times)$ and C. gentilii $(4 \times)$ cross in natural contact zones with an asymmetric formation of sterile tetraploid hybrids (Centaurea $\times$ paucispina). In this case, only C. gentilii acts as the mother $[46,49]$.

Centaurea aspera and C. gentilii are also able to cross. The inter-specific crosses between both species resulted in the symmetrical formation of hybrids with fertile ovules and pollen from both progenitors. However, their distribution is allopatric without known natural contact zone. The triploid hybrid between these two taxa was obtained for the first time in the greenhouse of the present study, and was named C. $\times$ masfitensis [53]. The fertility of the new hybrid between C. aspera and C. gentilii is unknown, and new experiments are necessary to clarify this point. 


\subsection{Influence on Polyploid Establishment}

Our results showed that the allotetraploid $C$. seridis produces almost twice the number of cypselae in the intra-specific crosses compared to $C$. aspera and C. gentilii. It is a bigger hairier plant that provides greater adaptability to coastal sandy habitats [32,38]. In the contact zones with C. aspera, asymmetric hybridization, along with the short distance dispersal of the hybrid cypselae, produces a differentiated microscale distribution with the sterile hybrid closer to the mother C. aspera [38]. All these characteristics surely favored the initial establishment and competition of $C$. seridis in sympatry with its progenitors. Selfing and high heterozygosity [47] probably enabled C. seridis to overcome initial bottlenecks, while phenotype differentiation, microspatial segregation, and especially the asymmetric formation of hybrids were powerful strategies to overcome the minority-cytotype-exclusion (MCE) effect described by Levin [54].

Our results also revealed that tetraploid C. gentilii and diploid C. aspera produce a similar number of cypselae in intra-specific crosses with no significant differences. Centaurea gentilii has a phenotype that is indistinguishable in the field from that of C. aspera [49]. Hybrid cypselae production was consistently lower, but without any significant differences with the intra-specific seed set. However, almost half the hybrid cypselae were empty $(49 \%)$, which probably revealed postzygotic barriers. This agrees with the results observed in other Asteraceae inter-specific crosses [55].

Therefore, C. gentilii does not have the same advantages as C. seridis, which would help it to establish and compete with its diploid parental. Natural autotetraploids arise within diploid populations, and often share the ecological niche [12,13]. In sympatry, diploids and autopolyploids compete for the same biotic and abiotic resources, and the minority-cytotype-exclusion effect acts on the less abundant cytotype [54]. This has led several authors to assert that the combined challenges of $\mathrm{MCE}$, meiotic abnormalities, and competition with diploids may cause most nascent polyploids to become extinct [7].

With an indistinguishable field phenotype, a similar seed set, self-incompatibility, and possible and symmetric inter-specific crosses, how did C. gentilii overcome the initial bottlenecks and escape from MCE? How did C. gentilii manage to establish and compete with the diploid cytotype? A substantial competitive advantage was probably required, but what was it?

Several hypotheses were highlighted to at least partially explain the establishment of neo-auto-polyploids. The first is the recurrent formation of autopolyploids within diploid populations under environmental stress [37,56]; these nascent autopolyploids were probably of multiple origin that would increase genetic diversity and bring about a new cytotype population size $[57,58]$. The second would be a polyploid's greater phenotypic plasticity that could also help it to establish, but very little evidence was provided for this. Indeed, when grown in the greenhouse, $C$. gentilii at first glance showed distinct phenotypical traits that were not observed in the field (unpublished results). Some studies already reported substantial modifications to polyploid phenotypes when grown in greenhouses [59], which could indicate greater phenotypic plasticity compared to that of their diploid progenitors. In Knautia serpentinicola, closely related diploids and tetraploids responded differently to key environmental factors, with the autotetraploid being more competitive than the diploid is [60].

Lastly, the hypothesis that one of the "per se advantages" of autopolyploids is the increased tolerance to inbreeding was expressed several times, but no broad consensus has been reached. Autopolyploids may effectively mask deleterious alleles better than diploids can, while allopolyploids are expected to display similar chromosomal behavior to that of diploids, and may not exhibit increased tolerance to inbreeding [61-63]. Very few comparative data on inbreeding depression in closely related polyploid and diploid taxa are available $[25,64]$, but at least two studies indicated less inbreeding depression in autopolyploids in relation to in diploids $[65,66]$. However, there are some cases in which more inbreeding depression was observed in autopolyploids than in diploids [67].

Natural Centaurea gentilii populations in Morocco grow under extreme environmental conditions. Long drought periods with extreme aridity, heat waves, and heavy recurrent grazing can dramatically reduce the number of individuals. When resampling C. gentilii populations from 2016 to 2017, we 
found some populations in catastrophic condition, and most individuals had died. Under such stressful conditions, possessing more tolerance to inbreeding could facilitate the re-establishment of populations from a very small number of individuals by probably contributing to $C$. gentilii establishment. Further genetic studies into Moroccan populations would help to shed some light on the genetic diversity, population differentiation, and gene flow of $C$. gentilii in relation to past bottlenecks and inbreeding.

Although these hypotheses were discussed to explain C. gentilii establishment, it remains an unresolved question. Further questions, like the origin of allotetraploid C. seridis through secondary contact between formerly allopatric taxa, which is called the secondary-contact hypothesis [68], or the fertility or sterility of the new hybrid (C. $\times$ masfitensis) acting or not as a triploid bridge between C. aspera and C. gentilii, will be investigated to provide new data to help us better understand the establishment and expansion of these polyploids.

\section{Materials and Methods}

\subsection{Geographical Distribution and Ploidy Level of Moroccan Populations}

The geographical distribution, ploidy level, and genetic analyses of the Spanish populations of C. aspera and C. seridis were already reported $[47,48]$. Moroccan populations were surveyed for the first time in 2013. Then, eight populations of C. gentilii were located on the Atlantic coast of Morocco [49]. During two new expeditions (2016 and 2017), the Atlantic and Mediterranean coasts of Morocco were exhaustively resurveyed from Tiznit (southern point) to Nador (northeastern point). To determine the populations' ploidy level, individuals were sampled during the 2016 expedition, 309 from four C. gentilii populations, and 96 from the C. seridis populations (Table 6). Thirty C. aspera individuals from the Spanish populations were resampled to confirm their ploidy level. The ploidy level of these individuals was determined by flow cytometry as described by Garmendia et al. (2015).

Table 6. Sampled population for ploidy-level analysis and cypselae collection.

\begin{tabular}{ccccccc}
\hline Population & Species & Code & UTM Coordinates & No. Ind & Cypselae & Country \\
\hline Takat & C. gentilii & TK & 29 R 4409003347409 & 66 & no & Morocco \\
Sous Massa & C. gentilii & SM & 29 R 4223603300019 & 64 & no & Morocco \\
Cap Beddouza & C. seridis & CB & 29 S 4922063617401 & 66 & no & Morocco \\
Zaouiat Kourati & C. gentilii & ZA/z & 29 R 4392993508884 & 65 & yes & Morocco \\
Tamri & C. gentilii & TM/t & 29 R 4226403403933 & 114 & yes & Morocco \\
Bouznika & C. seridis & b & 29 R 6705803740367 & 15 & yes & Morocco \\
Axdir & C. seridis & a & 29 R 4165553895607 & 15 & yes & Morocco \\
El Saler & C. aspera & s & 30 R 7297514362619 & 15 & yes & Spain \\
Chulilla & C. aspera & c & 30 R 680542 4391645 & 15 & yes & Spain \\
\hline
\end{tabular}

Code, first code for ploidy-level analysis/second code for controlled pollinations; No. of ind., number of individuals sampled by flow cytometry (2016 expedition); Cypselae, populations where cypselae were collected (2017 expedition).

\subsection{Controlled Pollinations}

During the 2017 expedition, cypselae were collected for forced-pollination experiments. Cypselae were sampled from two natural populations of each species (Table 1). The sampled capitula from the natural populations were stored at $4{ }^{\circ} \mathrm{C}$ for 2 months. In all cases, the sampled capitula came from 4-5 mothers under open-pollination conditions. One hundred cypselae were randomly extracted from the mixture of capitula sampled from each population and germinated. Individuals of the three species were grown in the Centro para la Investigación y la Experimentación Forestal (CIEF; Quart de Poblet, Spain) greenhouse. At least 50 plants from each species and population were grown in pots for the experiments done in January 2018.

Four controlled pollination, treatments were performed in these plants: intra-specific crosses within the three species, and inter-specific crosses between C. aspera and C. gentilii. The treated capitula were randomly selected from those available to obtain at least 30 treated capitula per treatment and 
taxon. Treatments were run during the flowering period, from June to August 2018. Pollinations were performed with the newly open capitula bagged in semipermeable nylon bags prior to anthesis. Upon anthesis, capitula were brushed gently against one another once a day on 2 consecutive days. During the cross-pollinations, each treated capitulum received pollen from the one-paired capitula from a different individual. The flowers of the treated capitula were not emasculated.

Due to plant management, the Zaouiat individuals grew late and bloomed outside the 2018 season, which was why the inter-specific crosses between C. aspera and C. gentilii from Zaouiat were repeated in 2019. Additionally, in 2019, the intra-specific crosses in C. aspera and C. gentilii (both allogamous) were specifically repeated to compare the seed sets obtained using individuals from the same population or from different populations within the taxon. For C. aspera, four pollination treatments were performed: (ss), ovules and pollen from El Saler; (sc), ovules from El Saler and pollen from Chulilla; (cs), ovules from Chulilla and pollen from El Saler; (cc), ovules and pollen from Chulilla. For C. gentilii, four cross-treatments were also performed: (tt), ovules and pollen from Tamri; (tz), ovules from Tamri and pollen from Zaouiat; (zt), ovules from Zaouiat and pollen from Tamri; (zz), ovules and pollen from Zaouiat.

\subsection{Progeny Analysis}

After pollinations, capitula were rebagged for 6 weeks until fruit set. For each treatment, total cypselae per capitulum were counted. Cypselae were disinfected with $0.5 \% \mathrm{NaClO}$ solution for $20 \mathrm{~min}$, washed 3 times for $5 \mathrm{~min}$ in distilled water, and hydrated on parafilm-closed Petri dishes for $24 \mathrm{~h}$ at $20{ }^{\circ} \mathrm{C}$. Subsequently, each cypsela was cut at $2 / 3$ from the epicotyl, and the pericarp was removed. Both empty (without embryo) and intact (with fully developed embryos) cypselae were counted. In the intact cypselae, the $1 / 3$ distal cotyledonary tissue was used to determine the ploidy level of each embryo by flow cytometry, as described by Garmendia et al. (2015). Each sample consisted of a small piece of leaf $\left(0.5 \mathrm{~cm}^{2}\right)$ collected from the plant, to be analyzed together with a similar leaf piece taken from a diploid control plant. Samples were chopped together using a razor blade in a nucleus isolation solution (High-Resolution DNA Kit Type P, solution A; Sysmex Partec, Munster, Germany). Nuclei were filtered through a $30 \mu \mathrm{m}$ nylon filter and stained with a 4,6-diamine-2-phenylindol (DAPI) solution (High-Resolution DNA Kit Type P, solution B; Partec). After a 5 min incubation period, stained samples were run in a CyFlow Ploidy Analyzer (Partec) flow cytometer equipped with optical parameters for the detection of DAPI fluorescence. DNA fluorochrome DAPI was excited with UV-LED at $365 \mathrm{~nm}$. Histograms were analyzed with CyView software (Sysmex Partec, Munster, Germany), which determines sample peak position, coefficient of variation (CV), arithmetic mean, and median. The rest of the embryo (2/3) was placed on wet Petri dishes at room temperature and in natural light so they could germinate.

\subsection{Statistical Analyses}

The average, standard error, skewness, and kurtosis of the number of cypselae per capitulum were assessed for each pollination treatment and taxon. The normality of residuals and homogeneity of variances were checked by a Shapiro-Wilk test and Levene test, respectively. Due to the lack of normality for the C. aspera and C. gentilii residuals, nonparametric methods were selected to compare medians: the median number of cypselae was compared among treatments and repetitions by the Kruskal-Wallis rank sum [69] and post hoc Dunn's [70] tests. Pearson residuals were used to highlight the significant differences between observed/expected frequencies of full/empty cypselae. All statistical analyses, tables, and figures were constructed using Stat graphics XVII-X64 and R language [71] with RStudio [72].

\section{Conclusions}

Centaurea aspera and C. gentilii showed clear allopatric distribution, whereas C. seridis occupies the intermediate area between both species. All three species can hybridize, but crosses only naturally 
occur in contact zones with C. seridis. Allotetraploid C. seridis produces more cypselae, is bigger and autogamous, and selfing forces the asymmetric formation of sterile hybrids with both C. aspera and C. gentilii. These characteristics would help C. seridis to avoid the minority-cytotype-exclusion effect and to become established. Tetraploid C. gentilii produces the same number of cypselae per capitulum as the diploid does, has an indistinguishable field phenotype, is allogamous, and symmetrically produces hybrids with $C$. aspera. Therefore, $C$. gentilii does not have the same competitive advantages as those of C. seridis. There is no clear evolutionary advantage of C. gentilii over C. aspera. How did C. gentilii overcome the minority-cytotype-exclusion effect? Is there any per se evolutionary advantage of the autopolyploid? It is still unclear. The recurrent production of neopolyploids in stress environments and more tolerance to inbreeding were highlighted to at least partially explain the establishment of these polyploids.

Supplementary Materials: The following are available online at http://www.mdpi.com/2223-7747/9/9/1142/s1. Figure S1: Centaurea seridis intra-specific treatment $(\mathrm{S} \times \mathrm{S})$; Figure S2: C. aspera intra-specific treatment $(\mathrm{A} \times$ A); Figure S3: C. gentilii intra-specific treatment $(\mathrm{G} \times \mathrm{G})$; Figure S4: Intra-specific cypselae production among three taxa; Figure S5: Intra-specific cypselae production within and between populations of $C$. aspera and $C$. gentilii-2019 experiments; Figure S6: C. gentilii Zaouiat population crosses; Figure S7: Inter-specific cross between C. aspera and C. gentilii $(\mathrm{A} \times \mathrm{G}, \mathrm{G} \times \mathrm{A})$; Figure S8: Intra-specific vs. inter-specific treatments.

Author Contributions: Conceptualization, H.M.; methodology, A.G., M.F., D.B., P.P.F.-G. and H.M.; validation, M.F., A.G., P.P.F.-G. and H.M.; formal analysis H.M. and A.G.; investigation, A.G., M.F., D.B., P.P.F.-G. and H.M.; resources, A.G., M.F., P.P.F.-G. and H.M.; data curation, A.G.; writing-original-draft preparation, H.M.; writing-review and editing, A.G., M.F., D.B., P.P.F.-G. and H.M.; visualization, A.G. and H.M.; supervision, A.G., M.F., D.B., P.P.F.-G. and H.M.; project administration, M.F.; funding acquisition, M.F., A.G., P.P.F.-G. and H.M. All authors have read and agreed to the published version of the manuscript.

Funding: This research was funded by the Conselleria d'Educació, Cultura i Esport (Generalitat Valenciana) with project AICO/2019/227.

Acknowledgments: We thank the Centro para la Investigación y la Experimentación Forestal (CIEF; Quart de Poblet, Spain) workers for their help in seed germination and greenhouse plant management. We also thank Servicio Devesa-Albufera, Viveros municipales (Ayuntamiento de Valencia) who helped us with the El Saler population.

Conflicts of Interest: The authors declare no conflict of interest.

\section{References}

1. Jiao, Y.; Wickett, N.J.; Ayyampalayam, S.; Chanderbali, A.S.; Landherr, L.; Ralph, P.E.; Tomsho, L.P.; Hu, Y.; Liang, H.; Soltis, P.S. Ancestral polyploidy in seed plants and angiosperms. Nature 2011, 473, 97-100. [CrossRef] [PubMed]

2. Otto, S.P. The evolutionary consequences of polyploidy. Cell 2007, 131, 452-462. [CrossRef] [PubMed]

3. Soltis, P.S.; Soltis, D.E. The role of hybridization in plant speciation. Ann. Rev. Plant Biol. 2009, 60, 561-588. [CrossRef]

4. Levin, D.A. Plant speciation in the age of climate change. Ann. Bot. 2019, 124, 769-775. [CrossRef] [PubMed]

5. Stebbins, G.L., Jr. Types of polyploids: Their classification and significance. Adv. Genet. 1947, 1, 403-429. [PubMed]

6. Chester, M.; Gallagher, J.P.; Symonds, V.V.; da Silva, A.V.C.; Mavrodiev, E.V.; Leitch, A.R.; Soltis, P.S.; Soltis, D.E. Extensive chromosomal variation in a recently formed natural allopolyploid species, Tragopogon miscellus (Asteraceae). Proc. Natl. Acad. Sci. USA 2012, 109, 1176-1181. [CrossRef]

7. Arrigo, N.; Barker, M.S. Rarely successful polyploids and their legacy in plant genomes. Curr. Opin. Plant Biol. 2012, 15, 140-146. [CrossRef]

8. Parisod, C.; Holderegger, R.; Brochmann, C. Evolutionary consequences of autopolyploidy. New Phytol. 2010, 186, 5-17. [CrossRef]

9. Pegoraro, L.; De Vos, J.M.; Cozzolino, S.; Scopece, G. Shift in flowering time allows diploid and autotetraploid Anacamptis pyramidalis (Orchidaceae) to coexist by reducing competition for pollinators. Bot. J. Linn. Soc. 2019, 191, 274-284. [CrossRef] 
10. Clausen, J.; Keck, D.D.; Hiesey, W.M. Experimental Studies on the Nature of Species. II. Plant Evolution through Amphidiploidy and Autoploidy, with Examples from the Madiinae; Carnegie Institute of Washington: Washington, DC, USA, 1945.

11. Stebbins, G.L. Chromosomal Evolution in Higher Plants; Edward Arnold Ltd.: London, UK, 1971.

12. Molina-Henao, Y.F.; Hopkins, R. Autopolyploid lineage shows climatic niche expansion but not divergence in Arabidopsis arenosa. Am. J. Bot. 2019, 106, 61-70. [CrossRef]

13. Spoelhof, J.P.; Soltis, P.S.; Soltis, D.E. Pure polyploidy: Closing the gaps in autopolyploid research. J. Syst. Evol. 2017, 55, 340-352. [CrossRef]

14. Barker, M.S.; Arrigo, N.; Baniaga, A.E.; Li, Z.; Levin, D.A. On the relative abundance of autopolyploids and allopolyploids. New Phytol. 2016, 210, 391-398. [CrossRef] [PubMed]

15. Levy, A.A.; Feldman, M. Genetic and epigenetic reprogramming of the wheat genome upon allopolyploidization. Biol. J. Linn. Soc. 2004, 82, 607-613. [CrossRef]

16. Mavrodiev, E.V.; Chester, M.; Sußrez-Santiago, V.N.; Visger, C.J.; Rodriguez, R.; Susanna, A.; Baldini, R.M.; Soltis, P.S.; Soltis, D.E. Multiple origins and chromosomal novelty in the allotetraploid Tragopogon castellanus (Asteraceae). New Phytol. 2015, 206, 1172-1183. [CrossRef] [PubMed]

17. Zhang, H.; Bian, Y.; Gou, X.; Zhu, B.; Xu, C.; Qi, B.; Li, N.; Rustgi, S.; Zhou, H.; Han, F. Persistent whole-chromosome aneuploidy is generally associated with nascent allohexaploid wheat. Proc. Natl. Acad. Sci. USA 2013, 110, 3447-3452. [CrossRef] [PubMed]

18. Ozkan, H.; Tuna, M.; Galbraith, D.W. No DNA loss in autotetraploids of Arabidopsis thaliana. Plant Breed. 2006, 125, 288-291. [CrossRef]

19. Eilam, T.; Anikster, Y.; Millet, E.; Manisterski, J.; Feldman, M. Genome size in natural and synthetic autopolyploids and in a natural segmental allopolyploid of several Triticeae species. Genome 2009, 52, 275-285. [CrossRef]

20. Buggs, R.J.; Zhang, L.; Miles, N.; Tate, J.A.; Gao, L.; Wei, W.; Schnable, P.S.; Barbazuk, W.B.; Soltis, P.S.; Soltis, D.E. Transcriptomic shock generates evolutionary novelty in a newly formed, natural allopolyploid plant. Curr. Biol. 2011, 21, 551-556. [CrossRef]

21. Parisod, C.; Alix, K.; Just, J.; Petit, M.; Sarilar, V.; Mhiri, C.; Ainouche, M.; Chalhoub, B.; Grandbastien, M.-A. Impact of transposable elements on the organization and function of allopolyploid genomes. New Phytol. 2010, 186, 37-45. [CrossRef]

22. Stupar, R.M.; Bhaskar, P.B.; Yandell, B.S.; Rensink, W.A.; Hart, A.L.; Ouyang, S.; Veilleux, R.E.; Busse, J.S.; Erhardt, R.J.; Buell, C.R. Phenotypic and transcriptomic changes associated with potato autopolyploidization. Genetics 2007, 176, 2055-2067. [CrossRef]

23. Doyle, J.J.; Coate, J.E. Autopolyploidy: An epigenetic macromutation. Am. J. Bot. 2020. [CrossRef]

24. Hegarty, M.J.; Barker, G.L.; Wilson, I.D.; Abbott, R.J.; Edwards, K.J.; Hiscock, S.J. Transcriptome shock after interspecific hybridization in Senecio is ameliorated by genome duplication. Curr. Biol. 2006, 16, 1652-1659. [CrossRef] [PubMed]

25. Ramsey, J.; Schemske, D.W. Neopolyploidy in flowering plants. Annu. Rev. Ecol. Syst. 2002, 33, 589-639. [CrossRef]

26. Lloyd, A.; Bomblies, K. Meiosis in autopolyploid and allopolyploid Arabidopsis. Curr. Opin. Plant Biol. 2016, 30, 116-122. [CrossRef] [PubMed]

27. Barke, B.H.; Daubert, M.; Hörandl, E. Establishment of apomixis in diploid F2 hybrids and inheritance of apospory from F1 to F2 hybrids of the Ranunculus auricomus complex. Front. Plant Sci. 2018, 9, 1111. [CrossRef] [PubMed]

28. Hojsgaard, D.; Hörandl, E. The rise of apomixis in natural plant populations. Front. Plant Sci. 2019, 10, 358. [CrossRef]

29. Nybom, H.; Esselink, G.D.; Werlemark, G.; Vosman, B. Microsatellite DNA marker inheritance indicates preferential pairing between two highly homologous genomes in polyploid and hemisexual dog-roses, Rosa L. Sect. Caninae DC. Heredity 2004, 92, 139-150. [CrossRef]

30. Harlan, J.R.; DeWet, J.M. On Ö. Winge and a prayer: The origins of polyploidy. Bot. Rev. 1975, 41, 361-390. [CrossRef]

31. Ramsey, J.; Schemske, D.W. Pathways, mechanisms, and rates of polyploid formation in flowering plants. Annu. Rev. Ecol. Syst. 1998, 29, 467-501. [CrossRef] 
32. Ferriol, M.; Garmendia, A.; Gonzalez, A.; Merle, H. Allogamy-autogamy switch enhance assortative mating in the allotetraploid Centaurea seridis L. coexisting with the diploid Centaurea aspera L. and triggers the asymmetrical formation of triploid hybrids. PLoS ONE 2015, 10, e0140465. [CrossRef]

33. Norden, E.H.; Lyrene, P.M.; Chaparro, J.X. Ploidy, fertility, and phenotypes of F1 hybrids between tetraploid highbush blueberry cultivars and diploid Vaccinium elliottii. HortScience 2020, 1, 1-6. [CrossRef]

34. Schinkel, C.C.; Kirchheimer, B.; Dullinger, S.; Geelen, D.; De Storme, N.; Hörandl, E. Pathways to polyploidy: Indications of a female triploid bridge in the alpine species Ranunculus kuepferi (Ranunculaceae). Plant Syst. Evol. 2017, 303, 1093-1108. [CrossRef] [PubMed]

35. Crismani, W.; Girard, C.; Mercier, R. Tinkering with meiosis. J. Exp. Bot. 2013, 64, 55-65. [CrossRef] [PubMed]

36. Mason, A.S.; Pires, J.C. Unreduced gametes: Meiotic mishap or evolutionary mechanism? Trends Genet. 2015, 31, 5-10. [CrossRef]

37. Decanter, L.; Colling, G.; Elvinger, N.; Heiðmarsson, S.; Matthies, D. Ecological niche differences between two polyploid cytotypes of Saxifraga rosacea. Am. J. Bot. 2020, 107, 423-435. [CrossRef]

38. Garmendia, A.; Merle, H.; Ruiz, P.; Ferriol, M. Distribution and ecological segregation on regional and microgeographic scales of the diploid Centaurea aspera L., the tetraploid C. seridis L., and their triploid hybrids (Compositae). PeerJ 2018, 6, e5209. [CrossRef]

39. Pandit, M.K.; Pocock, M.J.; Kunin, W.E. Ploidy influences rarity and invasiveness in plants. J. Ecol. 2011, 99, 1108-1115. [CrossRef]

40. Ehrendorfer, F. Polyploidy and distribution. In Polyploidy: Biological Relevance; Lewis, H., Walter, H., Eds.; Plenum Press: London, UK, 1980; pp. 45-60.

41. Linder, H.P.; Barker, N.P. Does polyploidy facilitate long-distance dispersal? Ann. Bot. 2014, 113, 1175-1183. [CrossRef]

42. Hellwig, F.H. Centaureinae (Asteraceae) in the Mediterranean-History of ecogeographical radiation. Plant Syst. Evol. 2003, 246, 137-162. [CrossRef]

43. Romaschenko, K.; Ertuğrul, K.; Susanna, A.; Garcia-Jacas, N.; Uysal, T.; Arslan, E. New chromosome counts in the Centaurea Jacea group (Asteraceae, Cardueae) and some related taxa. Bot. J. Linn. Soc. 2004, 145, 345-352. [CrossRef]

44. Consortium, M.E.R.P.D.; Austin, J.D.; Bertin, A.; Bórquez, J.P.; Cárdenas, L.; Cardoza, T.B.; Chapman, F.; De Sousa, A.C.B.; De Souza, A.P.; Douglas, K.C. Permanent genetic resources added to molecular ecology resources database 1 February 2011-31 March 2011. Mol. Ecol. Resour. 2011, 11, 757-758.

45. Ferrer-Gallego, P.P.; Merle, H.; Laguna, E. Typification of Centaurea gentilii (Asteraceae). Phytotaxa 2018, 334, 83-86. [CrossRef]

46. Ferrer-Gallego, P.P.; Merle Farinós, H.B.; Ferriol Molina, M.; Garmendia, A. A new combination and change in Rank for a Moroccan hybrid in Centaurea (Asteraceae). Flora Montiberica. 2018, 71, 35-37.

47. Ferriol, M.; Merle, H.; Garmendia, A. Microsatellite evidence for low genetic diversity and reproductive isolation in tetraploid Centaurea seridis (Asteraceae) coexisting with diploid Centaurea aspera and triploid hybrids in contact zones. Bot. J. Linn. Soc. 2014, 176, 82-98. [CrossRef]

48. Ferriol, M.; Garmendia, A.; Ruiz, J.J.; Merle, H.; Boira, H. Morphological and molecular analysis of natural hybrids between the diploid Centaurea aspera L. and the tetraploid C. seridis L. (Compositae). Plant Biosyst. Int. J. Deal. Asp. Plant Biol. 2012, 146, 86-100.

49. Garmendia, A.; Ferriol, M.; Juarez, J.; Zając, A.; Kałużny, K.; Merle, H. A rare case of a natural contact zone in Morocco between an autopolyploid and an allopolyploid of Centaurea aspera with sterile tetraploid hybrids. Plant Biol. 2015, 17, 746-757. [CrossRef]

50. Garmendia, A.; Farinós, H.M.; Segura, I.; Ferriol, M. Biogeografía de Centaurea x subdecurrens Pau nothosubsp. subdecurrens como indicador del estado de degradación de las dunas litorales del levante español. In Proceedings of the Biogeografía: Una ciencia para la conservación del medio: (VI Congreso Español de Biogeografía), Alicante, Spain, 7-11 September 2010; pp. 463-469.

51. Merle Farinós, H.B.; Garmendia Salvador, A.; Ferriol Molina, M. Nuevo híbrido del género Centaurea L. (Compositae) sección Seridia (Juss.) Czerep. Flora Montiberica 2009, 44, 66-71.

52. Ferriol, M.; Garmendia, A.; Benavent, D.; Ferrer-Gallego, P.P.; Merle, H. Mating system of Centaurea aspera L. (Asteraceae) polyploid relatives-Short Communication. Plant Biosyst. 2020, in press.

53. Ferrer-Gallego, P.P.; Benavent, D.; Ferriol, M.; Garmendia, A.; Merle, H. Centaurea $\times$ masfitensis, Nothosp. nov. (sect. Seridia (Juss.) DC., Asteraceae). Flora Montiberica 2020, in press. 
54. Levin, D.A. Minoritycytotype exclusion in local plant populations. TAXON 1975, 24, 35-43. [CrossRef]

55. Nielsen, L.R.; Siegismund, H.R.; Hansen, T. Inbreeding depression in the partially self-incompatible endemic plant species Scalesia affinis (Asteraceae) from Galápagos islands. Evol. Ecol. 2007, 21, 1-12. [CrossRef]

56. Soltis, D.E.; Soltis, P.S. Polyploidy: Recurrent formation and genome evolution. Trends Ecol. Evol. 1999, 14, 348-352. [CrossRef]

57. Parisod, C.; Besnard, G. Glacial in situ survival in the Western Alps and polytopic autopolyploidy in Biscutella laevigata L. (Brassicaceae). Mol. Ecol. 2007, 16, 2755-2767. [CrossRef] [PubMed]

58. Segraves, K.A.; Thompson, J.N.; Soltis, P.S.; Soltis, D.E. Multiple origins of polyploidy and the geographic structure of Heuchera grossulariifolia. Mol. Ecol. 1999, 8, 253-262. [CrossRef]

59. Mráz, P.; Garcia-Jacas, N.; Gex-Fabry, E.; Susanna, A.; Barres, L.; Müller-Schärer, H. Allopolyploid origin of highly invasive Centaurea stoebe s.l. (Asteraceae). Mol. Phylogenetics Evol. 2012, 62, 612-623. [CrossRef]

60. Čertner, M.; Sudová, R.; Weiser, M.; Suda, J.; Kolář, F. Ploidy-altered phenotype interacts with local environment and may enhance polyploid establishment in Knautia serpentinicola (Caprifoliaceae). New Phytol. 2019, 221, 1117-1127. [CrossRef]

61. Comai, L. The advantages and disadvantages of being polyploid. Nat. Rev. Genet. 2005, 6, 836-846. [CrossRef]

62. Ronfort, J. The mutation load under tetrasomic inheritance and its consequences for the evolution of the selfing rate in autotetraploid species. Genet. Res. 1999, 74, 31-42. [CrossRef]

63. Soltis, P.S.; Soltis, D.E. The role of genetic and genomic attributes in the success of polyploids. Proc. Natl. Acad. Sci. USA 2000, 97, 7051-7057. [CrossRef]

64. Pannell, J.R.; Obbard, D.J.; Buggs, R.J.A. Polyploidy and the sexual system: What can we learn from Mercurialis annua? Biol. J. Linn. Soc. 2004, 82, 547-560. [CrossRef]

65. Husband, B.C.; Schemske, D.W. The effect of inbreeding in diploid and tetraploid populations of Epilobium angustifolium (Onagraceae): Implications for the genetic basis of inbreeding depression. Evolution 1997, 51, 737-746. [CrossRef] [PubMed]

66. Rosquist, G. Reproductive biology in diploid Anthericum ramosum and tetraploid A. liliago (Anthericaceae). Oikos 2001, 92, 143-152. [CrossRef]

67. Johnston, M.O.; Schoen, D.J. Correlated evolution of self-fertilization and inbreeding depression: An experimental study of nine populations of Amsinckia (Boraginaceae). Evolution 1996, 50, 1478-1491. [CrossRef] [PubMed]

68. Stebbins, G.L. Polyploidy and the distribution of the arctic-alpine flora: New evidence and a new approach. Bot. Helv. 1984, 94, 1-13.

69. Kruskal, W.H.; Wallis, W.A. Use of ranks in one-criterion variance analysis. J. Am. Stat. Assoc. 1952, 47, 583-621. [CrossRef]

70. Dunn, O.J. Multiple comparisons among means. J. Am. Stat. Assoc. 1961, 56, 52-64. [CrossRef]

71. R Core Team. R: A Language and Environment for Statistical Computing; R Core Team: Vienna, Austria, 2018.

72. RStudio Team. RStudio: Integrated Development Environment for r; RStudio Team: Boston, MA, USA, 2015.

(C) 2020 by the authors. Licensee MDPI, Basel, Switzerland. This article is an open access article distributed under the terms and conditions of the Creative Commons Attribution (CC BY) license (http://creativecommons.org/licenses/by/4.0/). 